\title{
Mid-infrared vibrational study of deuterium-containing PAH variants
}

\author{
Mridusmita Buragohain ${ }^{1 *}$, Amit Pathak ${ }^{1}$, Peter Sarre ${ }^{2}$, Takashi Onaka ${ }^{3}$ and Itsuki \\ Sakon $^{3}$ \\ ${ }^{1}$ Department of Physics, Tezpur University, Tezpur 784 028, India \\ (ms.mridusmita@gmail.com, amit@tezu.ernet.in,* Corresponding author) \\ ${ }^{2}$ School of Chemistry, The University of Nottingham, University Park, Nottingham, \\ NG7 2RD, United Kingdom \\ ${ }^{3}$ Department of Astronomy, Graduate School of Science, The University of Tokyo, \\ Tokyo 113-0033, Japan
}

\begin{abstract}
Polycyclic Aromatic Hydrocarbon (PAH) molecules have been long proposed to be a major carrier of 'Unidentified Infrared' (UIR) emission bands that have been observed ubiquitously in various astrophysical environments. These molecules can potentially be an efficient reservoir of deuterium. Once the infrared properties of the deuteriumcontaining PAHs are well understood both experimentally and theoretically, the interstellar UIR bands can be used as a valuable tool to infer the cause of the deuterium depletion in the ISM.

Density Functional Theory (DFT) calculations have been carried out on deuteriumcontaining ovalene variants to study the infrared properties of these molecules. These include deuterated ovalene, cationic deuterated ovalene, deuteronated ovalene and deuterated-deuteronated ovalene. We present a $\mathrm{D} / \mathrm{H}$ ratio calculated from our theoretical study to compare with the observationally proposed $\mathrm{D} / \mathrm{H}$ ratio.
\end{abstract}

Keywords: PAH, Interstellar molecules, IR spectra, Unidentified infrared bands, Astrochemistry

\section{Introduction}

Polycyclic Aromatic Hydrocarbon (PAH) molecules have long been recognized as carriers of the mid-infrared emission bands popularly known as Unidentified Infrared (UIR) emission bands, which are observed at 3.3, 6.2, 7.7, 8.6, 11.2 and $12.7 \mu \mathrm{m}$ and longer wavelengths as broad emission features towards diverse astrophysical sources (Tielens, 2008). After being discovered by Gillett et al. (1973) in the 8-13 $\mu \mathrm{m}$ range, these infrared (IR) bands have been observed towards numerous Galactic and extragalactic sources that vary in physical and chemical environments (Onaka et al., 1996; Mattila et al., 1996; Verstraete et al., 1996; Hony et al., 2001; Verstraete et al., 2001; 
Peeters et al., 2002; Abergel et al., 2002; Acke and van den Ancker, 2004; Sakon et al., 2004). Increasing number of IR observations indicate that widespread, extremely stable interstellar particles are responsible for such features (Allamandola et al., 1989). The search for the origin of these features began with the hypothesis of Duley and Williams (1981) that vibrations of chemical functional groups attached to small carbon grains might produce such features. Sellgren (1984) proposed transiently heated very small grains (size $\sim 10 \AA$ ) to be the carriers. Later, Léger and Puget (1984) and Allamandola et al. (1985) independently suggested that the features arise due to the vibrational relaxation of PAH molecules on absorption of background UV photons, giving rise to infrared fluorescence. However, identification of the exact molecular form of PAH has not been successful so far. Recent discoveries of some weak features in the $3-20 \mu \mathrm{m}$ range with the Short Wavelength Spectrometer (SWS) on board ISO point to the existence of an extended PAH family rather than a single form that may explain UIR features (Verstraete et al., 1996; Peeters et al., 2004).

PAH molecules bear a significant fraction of interstellar carbon of about 5$10 \%$ (Tielens, 2008) and take part in crucial chemical processes, including heating of the ISM through the photo-electric effect and in determining the charge balance inside molecular clouds (Lepp and Dalgarno, 1988; Verstraete et al., 1990; Bakes and Tielens, 1994; Peeters et al., 2004). PAH molecules are also proposed to be potential carriers of 'Diffuse Interstellar Bands' (DIBs) that are absorption features on the interstellar extinction curve (Crawford et al., 1985; Léger and d'Hendecourt, 1985; Salama et al., 1996, 2011; Cox et al., 2006; Pathak and Sarre, 2008). The recent identification of two DIBs with $\mathrm{C}_{60}^{+}$strongly supports the existence of large-sized PAHs in the ISM (Campbell et al., 2015; Ehrenfreund and Foing, 2015). Berné et al. (2015) recently proposed the top-down formation of fullerene $\left(\mathrm{C}_{60}\right)$ by dehydrogenation of large PAHs using a photochemical model. In addition, a recent observation has proposed that some of the interstellar deuterium (D) exists in the form of PAD or $\mathrm{D}_{\mathrm{n}}-\mathrm{PAH}$; i.e. a PAH molecule with deuterium attached (Peeters et al., 2004). PAHs are likely to accommodate some of the primordial D (Draine, 2006) which may explain the present lower value of $\mathrm{D} / \mathrm{H}$ in the interstellar gas. Due to the potential astrophysical as well as environmental implications, extensive study on regular and substituted PAHs has been carried out both experimentally and theoretically (Langhoff, 1996; Hudgins and Sandford, 1998a, b; Allamandola et al., 1999; Oomens et al., 2003; Mattioda et al., 2005; Pathak and Sarre, 2008; Bauschlicher et al., 2010; Alvaro Galué et al., 2010; Simon et al., 2011).

Current research on substituted PAHs suggests the presence of deuterated PAHs (PADs and $\mathrm{D}_{\mathrm{n}} \mathrm{PAHs}$ ) as possible carriers for some of the observed UIRs (Peeters et al., 2004; Draine, 2006; Onaka et al., 2014; Buragohain et al., 2015; Doney et al., 2016). Such species are crucial as they show characteristic features in the $4-5 \mu \mathrm{m}$ region which is a featureless region for other pure as well as known substituted PAHs. Along with deuterated PAHs, other forms of deuterium-containing PAH variants are equally important as they are expected to show similar features as that of deuterated PAH. In our latest report, (Buragohain et al., 2015), a new form of deuterium-containing PAH molecule, i.e. deuteronated PAHs $\left(\mathrm{DPAH}^{+}\right)$have been suggested as potential carriers for observed bands in the $4-5 \mu \mathrm{m}$ region. Deuteronated PAH molecules of increasing size have been discussed in Buragohain et al. (2015). In the present work, possible 
variants of deuterium-containing ovalene have been studied to determine the expected vibrational transitions and to compare with observational data.

\section{Deuterium-containing PAH variants}

A regular PAH molecule can be converted into a deuterated PAH by exchange of $\mathrm{D}$ from $\mathrm{D}_{2} \mathrm{O}$ ice with one of the peripheral hydrogens in PAH in presence of UV radiation (Sandford et al., 2000). There are other formation mechanisms as discussed by Tielens (1983, 1992, 1997) and Allamandola et al. (1987, 1989). A deuterated PAH molecule may be converted into an alternative form of molecule e.g. deuteronated PAH $\left(\mathrm{DPAH}^{+}\right.$, a PAH with a deuteron added to it) in the course of chemical reactions occurring in the ISM, through addition of D to PAH radical cations or low temperature ionmolecule reaction followed by deuterium fractionation (see Buragohain et al. (2015) for details). Spectral evidence of such species in the ISM has been discussed recently by Peeters et al. (2004); Onaka et al. (2014); Buragohain et al. (2015). Peeters et al. (2004) reported two bands in the region of $4-5 \mu \mathrm{m}$ associated with deuterated PAHs. The bands at $4.4 \mu \mathrm{m}$ and $4.65 \mu \mathrm{m}$ have been suggested to arise from the stretching of aromatic and aliphatic $\mathrm{C}-\mathrm{D}$ bonds respectively in a deuterated PAH (PAD or $\mathrm{D}_{\mathrm{n}} \mathrm{PAH}$ ). These two bands are analogous to the 3.3 and $3.4 \mu \mathrm{m}$ bands which are characteristics of aromatic and aliphatic $\mathrm{C}-\mathrm{H}$ stretching, respectively. The idea has gained further support from an agreement of observed D/H ratio (Peeters et al., 2004) with the proposed value of D/H ratio by Draine (2006). According to Draine (2006), some of the primordial $\mathrm{D}$ atoms are incorporated into PAHs which may explain the current lower value of $\mathrm{D} / \mathrm{H}$ in the interstellar gas compared with the primitive value of $\mathrm{D} / \mathrm{H}$. Draine (2006) proposed a D/H ratio of $\sim 0.3$ for PAHs which agrees with the observations of Peeters et al. (2004). AKARI observations (Onaka et al., 2014) tentatively detected the $\mathrm{C}-\mathrm{D}$ band vibrations at 4.4 and $4.65 \mu \mathrm{m}$ and give an upper limit for the $\mathrm{D} / \mathrm{H}$ ratio. These observations favor a much lower $\mathrm{D} / \mathrm{H}$ ratio and suggest that $\mathrm{D}$ is more likely to be accommodated in large PAHs.

\section{Computational Approach}

To assign carriers for the large set of observed UIR bands, comparison between observational, experimental and theoretical spectra of PAHs is of the utmost importance. However, experimental spectroscopy has limitations especially for large and complex PAHs for several reasons.Synthesis of large PAHs and reproducing interstellar conditions in the laboratory are the major constraints faced in experimental spectroscopy. Theoretical quantum chemical calculations provide the missing link. Density Functional Theory (DFT) is immensely valuable to study the vibrational properties of a large set of PAH candidate carriers in relation to UIR bands (DeFrees et al., 1993; Langhoff, 1996; Szczepanski et al., 1996; Bauschlicher et al., 1997; Bauschlicher and Langhoff, 1997; Langhoff et al., 1998; Hudgins et al., 2001, 2004; Pathak and Rastogi, 2005, 2006, 2007; Malloci et al., 2007, 2008; Pauzat et al., 2011; Klærke et al., 2013; Candian et al., 2014; Roser et al., 2014; Buragohain et al., 2015). In this work, a DFT combination of B3LYP/6-311G** has been used to 

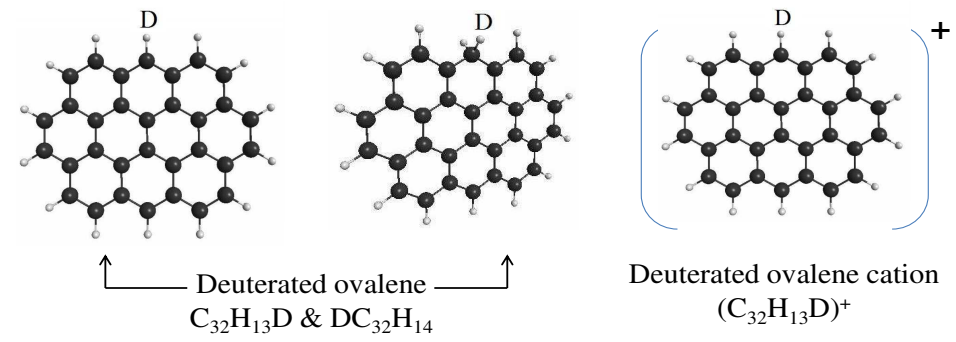

Deuterated ovalene cation $\left(\mathrm{C}_{32} \mathrm{H}_{13} \mathrm{D}\right)^{+}$

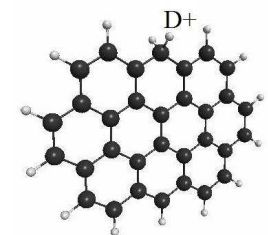

Deuteronated ovalene $\mathrm{DC}_{32} \mathrm{H}_{14}{ }^{+}$

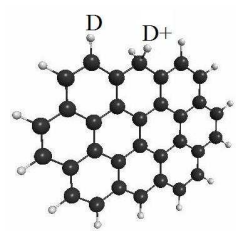

Deuterated-Deuteronated ovalene $\mathrm{DC}_{32} \mathrm{H}_{13} \mathrm{D}^{+}$

Figure 1: examples of deuterium-containing ovalene variants

optimize the molecular structure of PAHs. Frequencies and intensities of vibrational transitions have been computed using the optimized geometry at the same level of calculation. The calculated intensities are used as input to an emission model (Cook and Saykally, 1998; Pech et al., 2002; Pathak and Rastogi, 2008). The emission model uses black body radiation generated by a source having effective temperature of 40,000 K. The PAH molecule absorbs this radiation following their respective absorption cross-section. The excited PAH attains a peak temperature and cools down following a cascade mechanism emitting IR photons corresponding to their vibrational modes. These IR photons are added up to generate the emission spectrum. Details of the emission model may be found in Pathak and Rastogi (2008). The emitted energy and frequency thus obtained from emission model is used to plot a Gaussian profile of FWHM $30 \mathrm{~cm}^{-1}$. The profile width is typical for PAHs emitting in interstellar environment and depends on vibrational redistribution of the molecule Allamandola et al., 1989). Considering the emission model with a lower black body effective temperature 
of say $30,000 \mathrm{~K}$, we find no difference in the PAH emission spectrum except that the emitted energy is slightly reduced.

It is important to note that the theory overestimates the experimental frequency. To bring the frequencies into accordance with experimental values, theoretical frequencies are scaled down by using three different scaling factors for three different ranges of vibrational frequency. Scaling factors are calculated by comparing the frequencies of selected PAH molecules with available experimental data (Buragohain et al., 2015). Scaling factors used here are 0.974 for $\mathrm{C}-\mathrm{H}$ out of plane (OOP), 0.972 for $\mathrm{C}-$ $\mathrm{H}$ in-plane and $\mathrm{C}-\mathrm{C}$ stretching and 0.965 for $\mathrm{C}-\mathrm{H}$ stretching (Buragohain et al., 2015). In case of deuterium-containing PAHs, since we do not have laboratory data for aliphatic deuterium-containing PAHs, a scaling factor of 0.965 corresponding to $\mathrm{C}-\mathrm{H}$ stretching is used for $\mathrm{C}-\mathrm{D}$ stretching. The shift in frequencies of aliphatic bonds needs experimental support and may have some uncertainty. Relative intensities (Int $\mathrm{rel}_{\mathrm{1}}^{1}$ ) are obtained by taking the ratio of all intensities to the maximum intensity near $3060 \mathrm{~cm}^{-1}$ for neutral ovalenes. Similarly, for cations, we divide all the intensities by maximum intensity that appears near $1600 \mathrm{~cm}^{-1}$ for normalization. Several unresolved bands might add up resulting some band intensity to cross unity.

A mid-sized PAH ovalene $\left(\mathrm{C}_{32} \mathrm{H}_{14}\right)$ is chosen for this work. Figure 1 shows the structure of various deuterium-containing ovalene variants. This work includes DFT study of i) Deuterated ovalene (aromatic), ii) Deuterated ovalene (aliphatic), iii) Deuterated ovalene cation iv) Deuteronated ovalene, v) Deuterated-Deuteronated ovalene. Isomers of all the sample molecules are also considered in this work. The data presented here were produced using the QChem quantum chemistry suite of programs (Shao et al., 2015). The vibrational modes of the molecule are identified using graphical software available for computational chemistry packages.

\section{Results and Discussion}

\section{Neutral and cationic Ovalene}

These are pure ovalenes in neutral and ionized forms. The theoretically computed emission spectra of neutral ovalene $\left(\mathrm{C}_{32} \mathrm{H}_{14}\right)$ and cationic ovalene $\left(\mathrm{C}_{32} \mathrm{H}_{14}^{+}\right)$are presented in Figure 2 Neutral ovalene shows strong lines at $\sim 800-900 \mathrm{~cm}^{-1}(\sim 13-$ $11 \mu \mathrm{m})$ and $\sim 3050 \mathrm{~cm}^{-1}(\sim 3.3 \mu \mathrm{m})$ due to $\mathrm{C}-\mathrm{H}$ oop and $\mathrm{C}-\mathrm{H}$ stretching vibrational modes, respectively (Figure 2 a). Weak features at $\sim 1000-1600 \mathrm{~cm}^{-1}(\sim$ $10-6 \mu \mathrm{m})$ are characteristics of $\mathrm{C}-\mathrm{H}$ in-plane bending and $\mathrm{C}-\mathrm{C}$ stretching vibrational modes. These features are inherent for any form of neutral PAH molecules. Likewise, any form of cationic PAH molecule shows a greater number of features in the $\sim 1000-1600 \mathrm{~cm}^{-1}(\sim 10-6 \mu \mathrm{m})$ region as shown in Figure $2 \mathrm{~b}$. The region below $\sim 1000 \mathrm{~cm}^{-1}$ is attributed to $\mathrm{C}-\mathrm{H}$ oop modes. Unlike neutral PAHs, all cationic PAHs show a weak feature at $3080 \mathrm{~cm}^{-1}, \sim 3.3 \mu \mathrm{m}$ due to $\mathrm{C}-\mathrm{H}$ stretching vibrational modes. These are the standard features expected from any neutral and ionized PAH molecule 2

\footnotetext{
${ }^{1}$ Int $_{\text {rel }}=\frac{\text { absolute intensity }}{\text { maximum absolute inten }}$

${ }^{2}$ For converting $\mathrm{cm}^{-1}$ to $\mu \mathrm{m}, \frac{10,000}{\mathrm{~cm}^{-1}}$ is a simple conversion formula.
} 


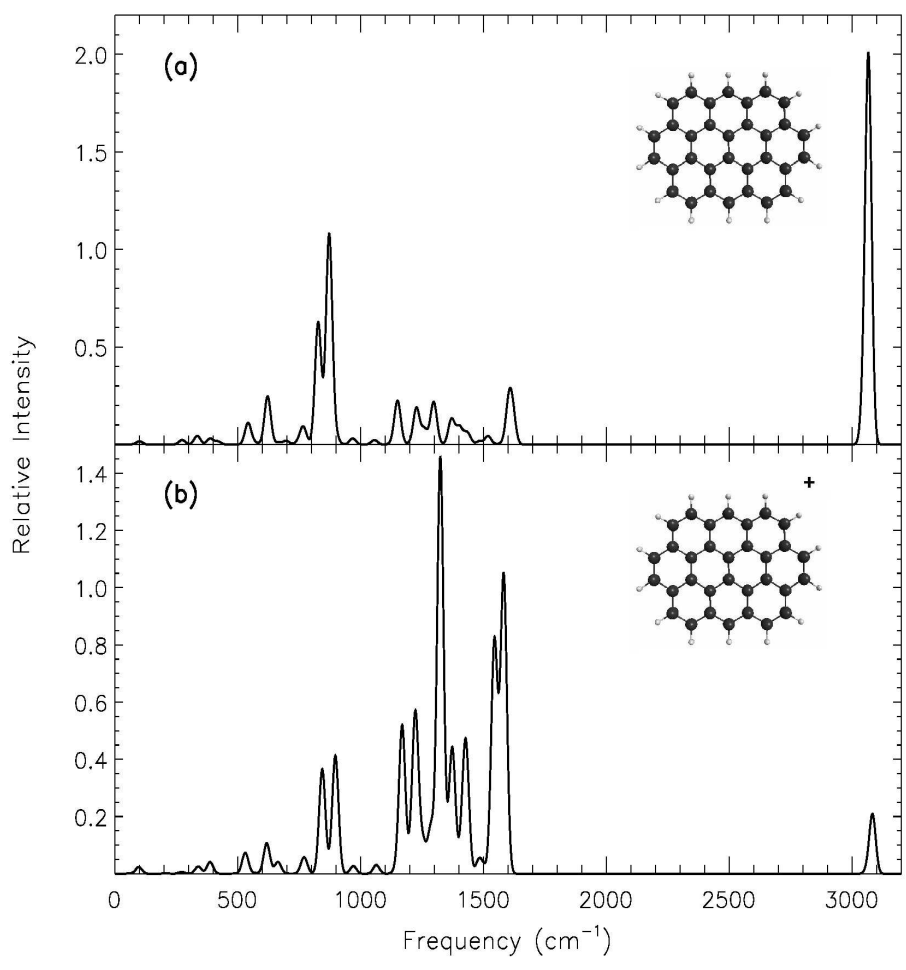

Figure 2: Theoretical emission spectra of (a) neutral ovalene $\left(\mathrm{C}_{32} \mathrm{H}_{14}\right)$, (b) ovalene cation $\left(\mathrm{C}_{32} \mathrm{H}_{14}^{+}\right)$

\section{Deuterated Ovalene}

A deuterium atom can attach to the periphery of a neutral PAH molecule either in an aromatic or aliphatic site that leads to the formation of a deuterated PAH molecule $\left(\mathrm{PAD}\right.$ or $\mathrm{D}_{\mathrm{n}} \mathrm{PAH}$ ) (Peeters et al., 2004). Figure 3 shows the emission spectra of deuterated ovalene, both aromatic 3 and aliphatic $4\left(\mathrm{C}_{32} \mathrm{H}_{13} \mathrm{D}\right.$ and $\left.\mathrm{DC}_{32} \mathrm{H}_{14}\right)$. Ovalene has four unique sites of deuteration which give four isomers of deuterated ovalene, both aromatic and aliphatic. In Figure 3 , the emission spectra of all the isomers of deuterated ovalene are also presented.

Both aromatic and aliphatic deuterated ovalene along with its isomers show usual features similar to those present in neutral ovalene. Substitution of D reduces the symmetry of ovalene that activates modes that were IR-inactive in neutral ovalene

\footnotetext{
${ }^{3} \mathrm{D}$ replacing $\mathrm{H}$ atom so that the resulting $\mathrm{C}-\mathrm{D}$ bond remains aromatic in nature

${ }^{4}$ addition of an extra $\mathrm{D}$ to neutral ovalene so that the resulting $\mathrm{C}-\mathrm{D}$ bond remains aliphatic in nature
} 


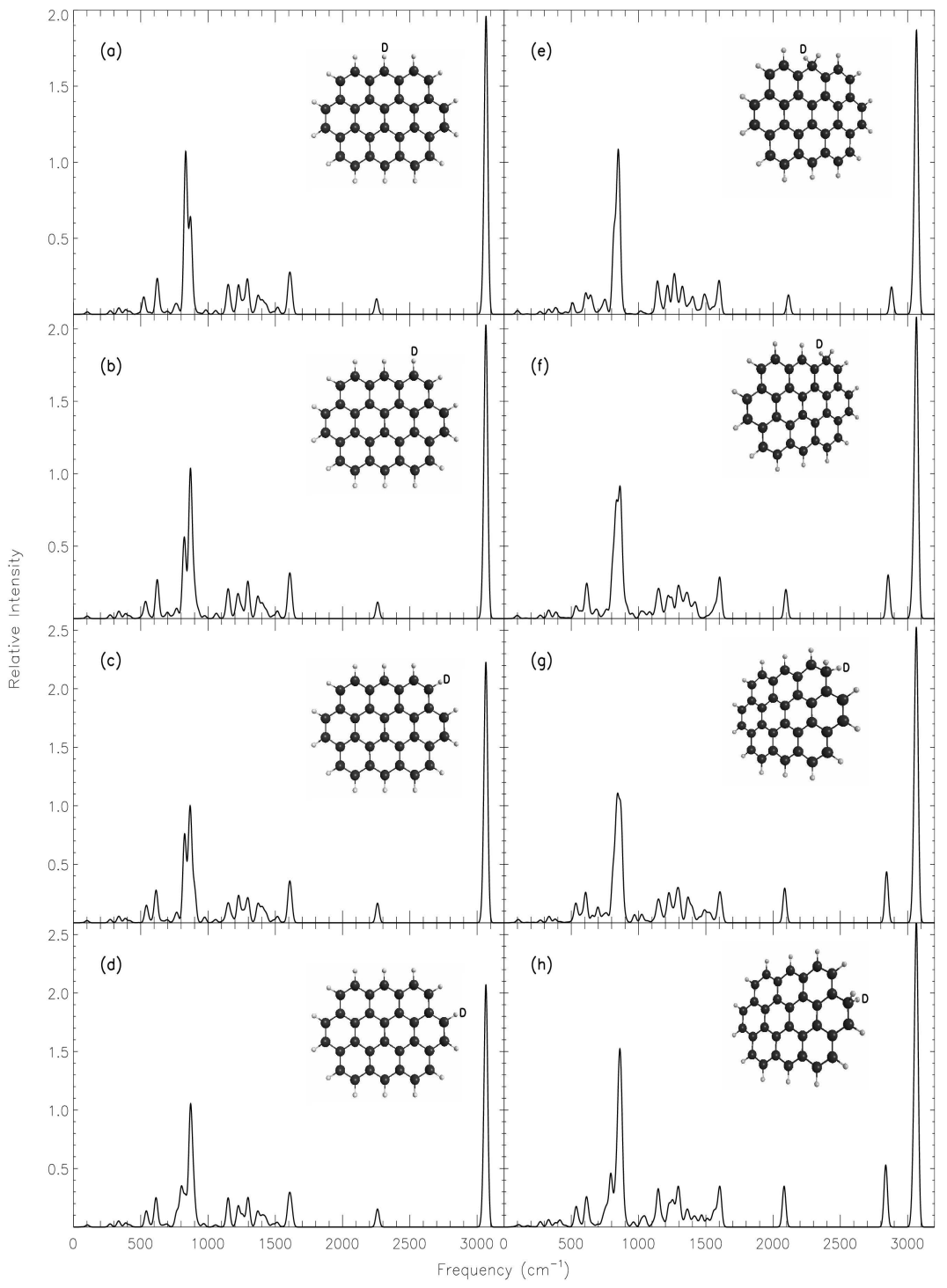

Figure 3: Theoretical spectra of (a) deuterated ovalene (aromatic, $\mathrm{C}_{32} \mathrm{H}_{13} \mathrm{D}$ ), (b) isomer 1 of $\mathrm{C}_{32} \mathrm{H}_{13} \mathrm{D}$, (c) isomer 2 of $\mathrm{C}_{32} \mathrm{H}_{13} \mathrm{D}$, (d) isomer 3 of $\mathrm{C}_{32} \mathrm{H}_{13} \mathrm{D}$, (e) deuterated ovalene (aliphatic, $\mathrm{DC}_{32} \mathrm{H}_{14}$ ), (f) isomer 1 of $\mathrm{DC}_{32} \mathrm{H}_{14}$, (g) isomer 2 of $\mathrm{DC}_{32} \mathrm{H}_{14}$, (h) isomer 3 of $\mathrm{DC}_{32} \mathrm{H}_{14}$ 
(Mulas et al., 2003). In deuterated ovalenes, weak C $-\mathrm{D}$ oop $\left(\sim 600-700 \mathrm{~cm}^{-1}, \sim\right.$ $16-14 \mu \mathrm{m})$ and $\mathrm{C}-\mathrm{D}$ in-plane modes $\left(\sim 860-900 \mathrm{~cm}^{-1}, \sim 11 \mu \mathrm{m}\right)$ appear due to the presence of $\mathrm{D}$ in the structure. These modes are red shifted compared to analogous $\mathrm{C}-\mathrm{H}$ modes due to the heavier deuterium. Figure $3(\mathrm{a}-\mathrm{d})$ are representatives of the same molecule, i.e. aromatic deuterated ovalene, but differ only in the position of D. In Figure 3 (a-d), a unique feature appears at $\sim 2260 \mathrm{~cm}^{-1}, 4.4 \mu \mathrm{m} 5$ (Int rel $(\mathrm{em})^{0} 0.136$ ) which is characteristic of $\mathrm{C}-\mathrm{D}$ stretching in $\mathrm{C}_{32} \mathrm{H}_{13} \mathrm{D}$. This feature is analogous to the strong $\mathrm{C}-\mathrm{H}$ stretching modes at $\sim 3.3 \mu \mathrm{m}$. In the case of $\mathrm{DC}_{32} \mathrm{H}_{14}$ and its isomers, as shown in Figure 3 (e-h), addition of an extra deuterium atom does not affect the spectrum much except in the $4-5 \mu \mathrm{m}$ region. Addition of deuterium to a neutral ovalene molecule breaks the aromatic nature at the site where $\mathrm{D}$ is added. Stretching of the $\mathrm{C}-\mathrm{D}$ and $\mathrm{C}-\mathrm{H}$ aliphatic bonds in $\mathrm{DC}_{32} \mathrm{H}_{14}$ gives features at $\sim 2095 \mathrm{~cm}^{-1}, 4.8 \mu \mathrm{m}$ (Int $\left._{\mathrm{rel}(\mathrm{em})} 0.24\right)$ and $2880.31 \mathrm{~cm}^{-1}, 3.5 \mu \mathrm{m}$ (Int rel (em) 0.36 ) respectively. Table 1 lists intensities and positions of $\mathrm{C}-\mathrm{D}$ stretching transitions for all the deuterated ovalenes (both aromatic and aliphatic) along with its isomers. The positions and intensities of $4.4 \mu \mathrm{m}$ (aromatic C-D stretching) and $4.7 / 4.8 \mu \mathrm{m}$ (aliphatic C-D stretching) feature are partially affected by the position of $\mathrm{D}$. There is a maximum wavenumber variation of $8 \mathrm{~cm}^{-1}$ for aromatic deuterated ovalene and $32 \mathrm{~cm}^{-1}$ for aliphatic deuterated ovalene. Similarly, Int $_{\mathrm{rel}(\mathrm{em})}$ also varies among the isomers, however no uniform pattern is observed (Figure 3).

\section{Deuterated Ovalene cation and Deuteronated Ovalene}

All the isomers of cationic forms of deuterated ovalene $\left(\mathrm{C}_{32} \mathrm{H}_{13} \mathrm{D}^{+}\right)$show more features compared to their neutral counterparts; particularly in the region $\sim 1000-$ $1600 \mathrm{~cm}^{-1}, \sim 10-6 \mu \mathrm{m}$ as shown in Figure 4 (a-d). This region is characteristics of $\mathrm{C}-\mathrm{H}$ in-plane and $\mathrm{C}-\mathrm{C}$ stretching vibrational modes. This is similar to that of ovalene cation, $\mathrm{C}_{32} \mathrm{H}_{14}^{+}$(Figure $2 \mathrm{~b}$ ). The effect of deuterium is however not observed in this region. The region below $\sim 1000 \mathrm{~cm}^{-1}$ is attributed to $\mathrm{C}-\mathrm{H}$ oop modes, which is again free from any significant D-associated modes. In Figure 4 (a-d), a weak feature at $\sim 2272 \mathrm{~cm}^{-1}, 4.4 \mu \mathrm{m}\left(\mathrm{Int}_{\mathrm{rel}(\mathrm{em})} 0.03\right)$ is attributed to the aromatic C $-\mathrm{D}$ stretching mode in $\mathrm{C}_{32} \mathrm{H}_{13} \mathrm{D}^{+}$. The $2000-3000 \mathrm{~cm}^{-1}(5-3 \mu \mathrm{m})$ region is magnified to highlight the weak features. Unlike the neutral counterparts of deuterated ovalene, cationic deuterated ovalenes show a weak feature at $3080 \mathrm{~cm}^{-1}, \sim 3.3 \mu \mathrm{m}$. The position of the $4.4 \mu \mathrm{m}$ band is not much affected by the position of $\mathrm{D}$ in solo and duo site with a maximum wavenumber separation of $11 \mathrm{~cm}^{-1}$. Similarly, Int $\mathrm{rel}_{(\mathrm{em})}$ does not vary much as can be seen in Table 1

A new form of PAH candidate carrier of mid infrared emission bands; deuteronated PAH $\left(\mathrm{DPAH}^{+}\right.$) has recently been discussed by Buragohain et al. (2015). Structurally, a deuteronated PAH is a PAH with a deuteron added to its periphery. Formation of these PAHs is favorable in the ionized ISM. Its closed shell electronic structure makes a deuteronated PAH molecule chemically less reactive than the corresponding PAH cation which is an open shell structure. However, photostability does not change

\footnotetext{
${ }^{5}$ wavenumbers are averaged among the isomers of the same molecule

${ }^{6}$ Relative intensity from emission model, average is taken for the same molecule including its isomers
} 


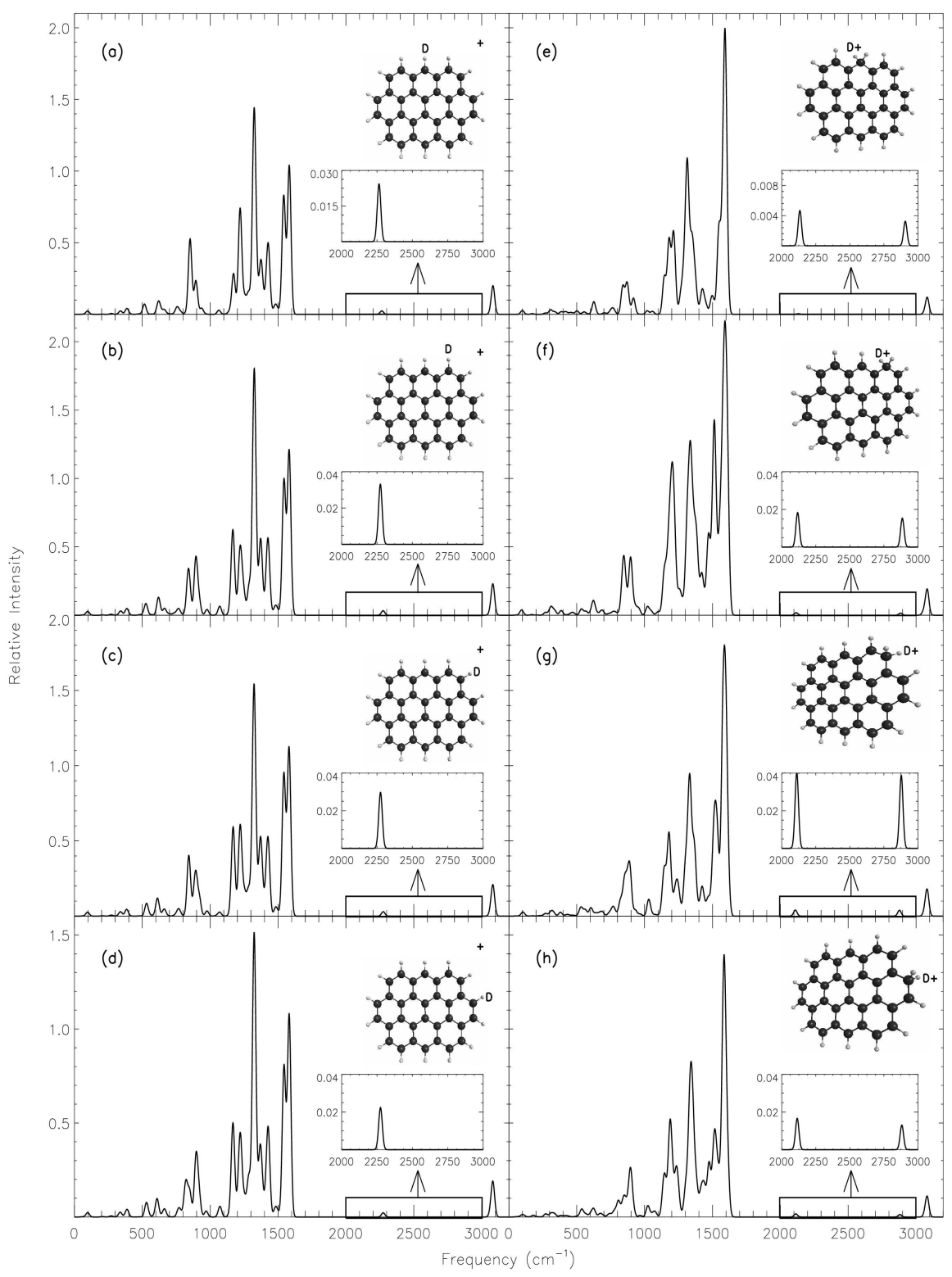

Figure 4: Theoretical spectra of (a) deuterated ovalene cation, $\left(\mathrm{C}_{32} \mathrm{H}_{13} \mathrm{D}^{+}\right)$, (b) isomer 1 of $\mathrm{C}_{32} \mathrm{H}_{13} \mathrm{D}^{+}$, (c) isomer 2 of $\mathrm{C}_{32} \mathrm{H}_{13} \mathrm{D}^{+}$, (d) isomer 3 of $\mathrm{C}_{32} \mathrm{H}_{13} \mathrm{D}^{+}$, (e) deuteronated ovalene, $\left(\mathrm{DC}_{32} \mathrm{H}_{14}^{+}\right.$), (f) isomer 1 of $\mathrm{DC}_{32} \mathrm{H}_{14}^{+}$, (g) isomer 2 of $\mathrm{DC}_{32} \mathrm{H}_{14}+$, (h) isomer 3 of $\mathrm{DC}_{32} \mathrm{H}_{14}^{+}$ 
much between similar open shell and closed shell species. Theoretical IR spectra of deuteronated ovalene $\left(\mathrm{DC}_{32} \mathrm{H}_{14}^{+}\right)$and its isomers are presented in Figure $4(\mathrm{e}-\mathrm{h})$. Addition of a deuteron $\left(\mathrm{D}^{+}\right)$to a neutral PAH at different positions reduces the symmetry and a rich IR spectrum, particularly in the region $\sim 1000-1600 \mathrm{~cm}^{-1}, \sim 10-6 \mu \mathrm{m}$ is noted. A number of features in this region are contributed by $\mathrm{C}-\mathrm{H}$ in-plane and $\mathrm{C}-\mathrm{C}$ stretching modes. However, a new D-associated feature is observed at $1212.41 \mathrm{~cm}^{-1}, 8.3 \mu \mathrm{m}\left(\mathrm{Int}_{\mathrm{rel}(\mathrm{em})} 0.41\right)$, which arises due to a combination of $\mathrm{D}-\mathrm{C}-\mathrm{H}$ oop, $\mathrm{C}-\mathrm{H}$ in-plane and $\mathrm{C}-\mathrm{C}$ stretching vibrations. Prominent features with $\mathrm{Int}_{\mathrm{rel}(\mathrm{em})}$ between 0.1 and 0.2 due to $\mathrm{C}-\mathrm{H}$ oop modes are present in the $\sim 800-900 \mathrm{~cm}^{-1}, \sim 13-11 \mu \mathrm{m}$ region. This region is not affected by any significant D-associated modes. A pure D-associated mode appears at $\sim 2118 \mathrm{~cm}^{-1}$, i.e., $4.7 \mu \mathrm{m}$ with a very low $\operatorname{Int}_{\mathrm{rel}(\mathrm{em})}$ of 0.02 . This feature is attributed to the stretching of the aliphatic $\mathrm{C}-\mathrm{D}$ bond in $\mathrm{DC}_{32} \mathrm{H}_{14}^{+}$. Stretching of aliphatic and aromatic $\mathrm{C}-\mathrm{H}$ bonds gives weak features at $\sim 2887 \mathrm{~cm}^{-1}(3.5 \mu \mathrm{m})$ and $\sim 3080 \mathrm{~cm}^{-1}(3.3 \mu \mathrm{m})$, respectively. In Figure 4 the $2000-3000 \mathrm{~cm}^{-1}$ region is zoomed in to show the weak features. Isomers of $\mathrm{DC}_{32} \mathrm{H}_{14}^{+}$show a variation in the position of the $4.7 \mu \mathrm{m}$ with a maximum wavenumber variation of $23 \mathrm{~cm}^{-1}$. Intensities remain almost the same irrespective of the structural difference of $\mathrm{DC}_{32} \mathrm{H}_{14}^{+}$.

\section{Dovalene $^{+}$}

Dovalene $\mathrm{D}^{+}\left(\mathrm{DC}_{32} \mathrm{H}_{13} \mathrm{D}^{+}\right)$carries two types of $\mathrm{C}-\mathrm{D}$ bonds, aromatic at the addition site of $\mathrm{D}$ and aliphatic at the addition site of $\mathrm{D}^{+}$. The computed IR spectra of of DovaleneD ${ }^{+}$and its isomer are shown in Figure 5 (a,b). Several isomers for Dovalene $\mathrm{D}^{+}$are possible, though only two are randomly chosen. The structure of Dovalene $\mathrm{D}^{+}$is a combination of deuterated ovalene (aromatic) and deuteronated ovalene and shows similar characteristic vibrational modes that are present in deuterated ovalene (aromatic) and deuteronated ovalene. The spectrum (Figure 5) is dominated by rich $\mathrm{C}-\mathrm{H}$ in-plane and $\mathrm{C}-\mathrm{C}$ stretching modes that appear in the $\sim 1000-1600 \mathrm{~cm}^{-1}, \sim 10-6 \mu \mathrm{m}$ region. $\mathrm{C}-\mathrm{H}$ oop modes are comparatively weak and are distributed in the $\sim 600-900 \mathrm{~cm}^{-1}, \sim 16-11 \mu \mathrm{m}$ region. The presence of deuteriums in Dovalene ${ }^{+}$causes new features to appear in the $\sim 600-1600 \mathrm{~cm}^{-1}, \sim 16-6 \mu \mathrm{m}$ region. The most significant features (above relative intensity 0.05 ) are $\mathrm{C}-\mathrm{D}$ in-plane and $\mathrm{D}-\mathrm{C}-\mathrm{H}$ oop. The former is analogous to the $\mathrm{C}-\mathrm{H}$ in-plane mode, but is redshifted due to the heavier mass of $\mathrm{D}$ and blended with the $\mathrm{C}-\mathrm{H}$ oop modes. This feature appears at $\sim 860 \mathrm{~cm}^{-1}(11.6 \mu \mathrm{m}$, Int $\left._{\mathrm{rel}(\mathrm{em})} 0.08\right)$ in DovaleneD ${ }^{+}$and at $\sim 850 \mathrm{~cm}^{-1}\left(11.8 \mu \mathrm{m}\right.$, Int $\left.\mathrm{rel}_{\mathrm{em})} 0.15\right)$ in its isomer. The latter (D $-\mathrm{C}-\mathrm{H}$ oop) appears at $\sim 1212 \mathrm{~cm}^{-1}\left(8.3 \mu \mathrm{m}\right.$, Int $\left.\mathrm{rel}_{\text {rel }} 0.42\right)$ in DovaleneD ${ }^{+}$and at $\sim 1200 \mathrm{~cm}^{-1}\left(8.3 \mu \mathrm{m}\right.$, Int $\left.\mathrm{rel}_{\mathrm{rel}} 0.66\right)$ in its isomer. These features are however not pure and are mixed with the $\mathrm{C}-\mathrm{H}$ in-plane and the $\mathrm{C}-\mathrm{C}$ stretching modes. Pure contributions of D atoms in DovaleneD ${ }^{+}$are observed at $\sim 2133 \mathrm{~cm}^{-1}(4.7 \mu \mathrm{m}$, Int $\left._{\text {rel }} 0.005\right)$ and at $\sim 2269 \mathrm{~cm}^{-1}(4.4 \mu \mathrm{m}$, Int rel 0.01). These two features arise due to the stretching of aliphatic $\mathrm{C}-\mathrm{D}$ and aromatic $\mathrm{C}-\mathrm{D}$ bonds respectively and are extremely weak compared to $\mathrm{C}-\mathrm{C}$ stretching modes. The stretching of the aliphatic $\mathrm{C}-\mathrm{H}$ bond gives rise to a very weak feature at $\sim 2907 \mathrm{~cm}^{-1}\left(3.4 \mu \mathrm{m}\right.$, Int $\left.\mathrm{rel}_{\mathrm{rel}} 0.004\right)$. In the isomer counterpart (Figure 5b), stretching of aliphatic $\mathrm{C}-\mathrm{D}$, aromatic $\mathrm{C}-\mathrm{D}$ 


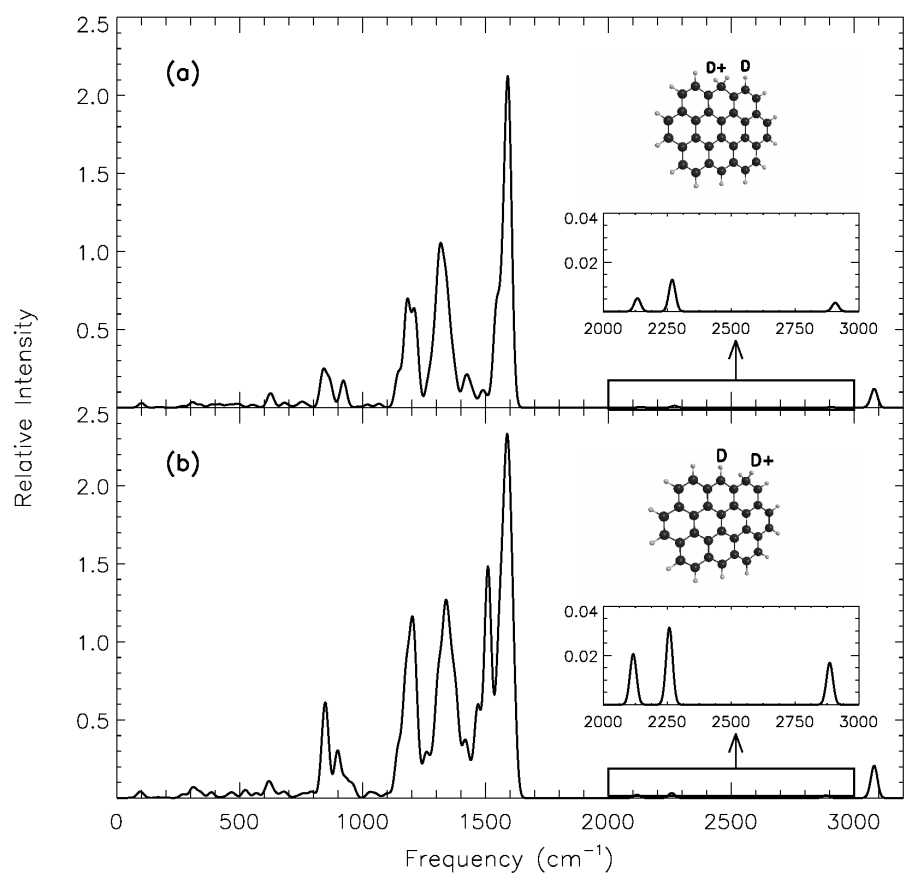

Figure 5: Theoretical spectra of DovaleneD ${ }^{+}\left(\mathrm{DC}_{32} \mathrm{H}_{13} \mathrm{D}^{+}\right)$and its isomer

and aliphatic $\mathrm{C}-\mathrm{H}$ bonds are seen at $\sim 2117 \mathrm{~cm}^{-1}(4.7 \mu \mathrm{m}), \sim 2258 \mathrm{~cm}^{-1}(4.4 \mu \mathrm{m})$ and $\sim 2885 \mathrm{~cm}^{-1}(3.5 \mu \mathrm{m})$ with Int $_{\mathrm{rel}} 0.02,0.03$ and 0.02 respectively. The region of $2000-3000 \mathrm{~cm}^{-1}$ is zoomed-in as shown in Figure 5, to highlight the weak features at $4.7,4.4 \& 3.5 \mu \mathrm{m}$. As expected, another weak but distinct feature appears at $\sim 3080 \mathrm{~cm}^{-1}(3.3 \mu \mathrm{m})$ which is due to aromatic $\mathrm{C}-\mathrm{H}$ stretching vibrational modes and is inherent in all cationic PAHs.

Dovalene $\mathrm{D}^{+}$has a possibility of several isomers and a slight variation is present in the the aliphatic and aromatic $\mathrm{C}-\mathrm{D}$ stretching bands depending on the position of substitution/addition of the $\mathrm{D}$ atom. This leads to the broadening of the $\mathrm{C}-\mathrm{D}$ stretching band if contribution from all the isomers is considered.

Figure 6 compares the spectra of deuterated ovalene cation and deuteronated ovalene with that of protonated ovalene $\left(\mathrm{HC}_{32} \mathrm{H}_{14}^{+}\right)$. A protonated $\mathrm{PAH}$ is a $\mathrm{PAH}$ with a proton added to its periphery and is structurally identical to a deuteronated PAH. We have considered protonation only at one position and compared with respective counterparts of deuterated ovalene cation and deuteronated ovalene. The emission spectrum of protonated ovalene shows similar features that are present in deuteronated ovalene. An exception is the appearance of a weak feature at $\sim 2900 \mathrm{~cm}^{-1}\left(3.5 \mu \mathrm{m}, \mathrm{Int}_{\mathrm{rel}}\right.$ 0.006) due to symmetric $\mathrm{H}-\mathrm{C}-\mathrm{H}$ stretching at the addition site. Its associated antisym- 


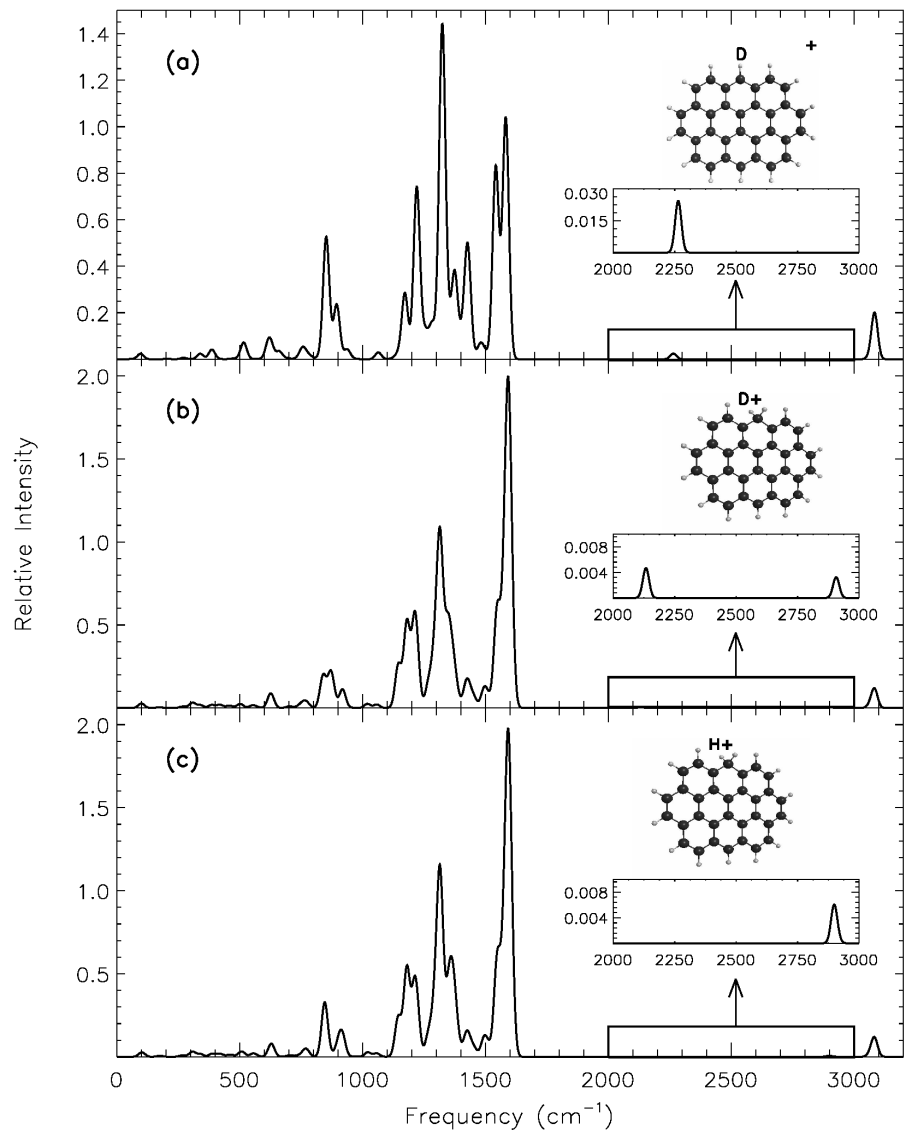

Figure 6: Theoretical spectra of (a) deuterated ovalene cation, $\left(\mathrm{C}_{32} \mathrm{H}_{13} \mathrm{D}^{+}\right)$, (b) deuteronated ovalene, $\left(\mathrm{DC}_{32} \mathrm{H}_{14}^{+}\right)$and protonated ovalene $\left(\mathrm{HC}_{32} \mathrm{H}_{14}^{+}\right)$ 
metric H-C-H stretching appears at $\sim 2915 \mathrm{~cm}^{-1}(3.4 \mu \mathrm{m})$ with very low relative intensity.

\section{Astrophysical Implications}

PAHs with incorporated deuterium might be crucial as it might provide an explanation for the missing primordial $\mathrm{D}$ which could not be solely answered by astration 7 . The current value of $\mathrm{D} / \mathrm{H}$ has been estimated to be $\sim 7 \mathrm{ppm}$ to $\sim 22 \mathrm{ppm}$ (Jenkins et al., 1999; Sonneborn et al., 2000; Wood et al., 2004; Linsky et al., 2006) along various lines of sight, whereas the primordial D/H ratio is suggested as $\sim 26 \mathrm{ppm}$ (Moos et al., 2002; Steigman, 2003; Wood et al, , 2004). Draine (2006) has proposed that the problem of reduced $\mathrm{D} / \mathrm{H}$ ratio can be explained if some of the primordial Ds are considered to be depleted in interstellar dust. Among all forms of interstellar dusts, some might be depleted onto PAHs which may produce a deuterated PAH molecule. Draine (2006) also proposed a $\mathrm{D} / \mathrm{H}$ ratio of $\sim 0.3$ in PAHs which is in accordance with the present estimated ratio of $\mathrm{D} / \mathrm{H}$ in interstellar gas. For observational search of such deuterium or other deuterium-containing PAH variants in the ISM, spectral observations of these molecules are desired.

In this report, we have considered deuterium-containing PAH variants for theoretical spectroscopic study. All frequencies corresponding to D-associated modes in deuterium-containing PAHs may not be used to compare with observations due to their low intensity. Another important fact is that $\mathrm{C}-\mathrm{D}$ in-plane and oop modes merge with other usual modes that are present in a pure PAH. Such features are inappropriate to distinguish any interstellar deuterium-containing PAH. An exception is the $\mathrm{C}-\mathrm{D}$ stretching mode $(4-5 \mu \mathrm{m})$ that uniquely may help to identify a PAH candidate with deuterium. The previous section emphasizes that all kinds of deuterium-containing PAH variants show unique features in the $4-5 \mu \mathrm{m}$ region. This region has not been identified with any significant lines apart from the lines $(4.4 \mu \mathrm{m}$ and $4.7 \mu \mathrm{m})$ expected from deuterium-containing PAHs as seen in the emission spectra of PAHs. However, there is a possibility of overtones and combination bands occurring at a similar position (Allamandola et al., 1989). Stretching of aromatic and aliphatic C $-\mathrm{D}$ bonds in a deuterium-containing PAH causes two features to appear at $\sim 4.4 \mu \mathrm{m}$ and $\sim 4.7 \mu \mathrm{m}$ respectively. Table 1 describes the position and intensities of the corresponding $\mathrm{C}-\mathrm{D}$ stretching modes in our sample molecules. The intensity of these features depends on the percentage of deuteration and also on the position of $\mathrm{D}$ in the isomers. The same features ( $4-5 \mu \mathrm{m}$ region) have been observationally detected by Peeters et al. (2004) at $\sim 4.4 \mu \mathrm{m}$ and $\sim 4.65 \mu \mathrm{m}$ towards the Orion bar and M17. The observed features are assigned to $\mathrm{C}-\mathrm{D}$ stretching vibrational modes in PADs or $\mathrm{D}_{\mathrm{n}}$ PAHs. AKARI also observed a small area of overlapping region as that of Peeters et al. (2004), and only detected some excess emissions at these wavelengths (Onaka et al., 2014). Bands at $\sim 4.4 \mu \mathrm{m}$ and $\sim 4.65 \mu \mathrm{m}$ are analogous to bands at $\sim 3.3 \mu \mathrm{m}$ (aromatic $\mathrm{C}-\mathrm{H}$ stretching) and $\sim 3.5 \mu \mathrm{m}$ (aliphatic $\mathrm{C}-\mathrm{H}$ stretching) respectively. The $4-5 \mu \mathrm{m}$ region

\footnotetext{
${ }^{7}$ conversion of $\mathrm{D}$ into other heavy elements due to nuclear fusion in stellar interiors
} 
Table 1: Intensities and positions of the $\mathrm{C}-\mathrm{D}$ stretching mode in deuteriumcontaining PAH variants

\begin{tabular}{|c|c|c|c|c|c|}
\hline PAH & $\begin{array}{l}\text { Frequency } \\
\left(\mathrm{cm}^{-1}\right)\end{array}$ & $\begin{array}{c}\text { Wavelength } \\
(\mu \mathrm{m})\end{array}$ & $\begin{array}{c}\text { Absolute } \\
\text { intensity }(\mathrm{km} / \mathrm{mole})\end{array}$ & $\mathrm{Int}_{\mathrm{rel}(\mathrm{abs})}{ }^{a}$ & $\operatorname{Int}_{\mathrm{rel}(\mathrm{em})}$ \\
\hline Deuterated ovalene $^{c}$ & 2253 & 4.44 & 9.816 & 0.08 & 0.10 \\
\hline $\begin{array}{l}\text { Deuterated ovalene } \\
\text { (isomer 1) }\end{array}$ & 2261 & 4.42 & 10.118 & 0.08 & 0.11 \\
\hline $\begin{array}{l}\text { Deuterated ovalene }{ }^{c} \\
\text { (isomer 2) }\end{array}$ & 2260 & 4.42 & 13.424 & 0.12 & 0.17 \\
\hline $\begin{array}{l}\text { Deuterated ovalenes } \\
\quad \text { (isomer 3) }\end{array}$ & 2260 & 4.42 & 13.297 & 0.11 & 0.15 \\
\hline Deuterated ovalene $^{d}$ & 2114 & 4.73 & 11.681 & 0.09 & 0.13 \\
\hline $\begin{array}{l}\text { Deuterated ovalene }{ }^{d} \\
\text { (isomer 1) }\end{array}$ & 2095 & 4.77 & 15.748 & 0.14 & 0.2 \\
\hline $\begin{array}{c}\text { Deuterated ovalene } \frac{d}{a} \\
\text { (isomer } 2 \text { ) }\end{array}$ & 2086 & 4.79 & 19.360 & 0.2 & 0.29 \\
\hline $\begin{array}{l}\text { Deuterated ovalene } \frac{d}{\sigma} \\
\text { (isomer 3) }\end{array}$ & 2082 & 4.80 & 21.566 & 0.24 & 0.35 \\
\hline $\begin{array}{c}\text { Deuterated ovalents } \\
\text { cation }\end{array}$ & 2264 & 4.42 & 5.166 & 0.03 & 0.02 \\
\hline $\begin{array}{l}\text { Deuterated ovalenes } \\
\text { cation (isomer 1) }\end{array}$ & 2274 & 4.40 & 5.887 & 0.04 & 0.03 \\
\hline $\begin{array}{l}\text { Deuterated ovalents } \\
\text { cation (isomer 2) }\end{array}$ & 2275 & 4.40 & 5.641 & 0.03 & 0.03 \\
\hline $\begin{array}{l}\text { Deuterated ovalentg } \\
\text { cation (isomer 3) }\end{array}$ & 2274 & 4.40 & 4.782 & 0.02 & 0.02 \\
\hline Deuteronated ovalene & 2133 & 4.69 & 1.434 & 0.005 & 0.005 \\
\hline $\begin{array}{l}\text { Deuteronated ovalene }{ }^{|d|} \\
\text { (isomer 1) }\end{array}$ & 2117 & 4.72 & 3.561 & 0.02 & 0.02 \\
\hline $\begin{array}{c}\begin{array}{c}\text { Deuteronated ovalene } \\
\text { (isomer 2) }\end{array} \\
\end{array}$ & 2110 & 4.74 & 8.755 & 0.04 & 0.04 \\
\hline $\begin{array}{l}\text { Deuteronated ovalene }{ }^{d \mid} \\
\quad \text { (isomer 3) }\end{array}$ & 2114 & 4.73 & 5.699 & 0.02 & 0.02 \\
\hline DovaleneD $^{+}$대며 & $\begin{array}{l}2269 \\
2133\end{array}$ & $\begin{array}{l}4.41 \\
4.69\end{array}$ & $\begin{array}{l}3.616 \\
1.460\end{array}$ & $\begin{array}{c}0.01 \\
0.006\end{array}$ & $\begin{array}{c}0.01 \\
0.005\end{array}$ \\
\hline Dovalene $^{+}$c & $\begin{array}{l}2258 \\
2117\end{array}$ & $\begin{array}{l}4.43 \\
4.73\end{array}$ & $\begin{array}{l}5.673 \\
3.609\end{array}$ & $\begin{array}{l}0.04 \\
0.02\end{array}$ & $\begin{array}{l}0.03 \\
0.02\end{array}$ \\
\hline
\end{tabular}

For structures of various isomers of deuterium containing PAHs, please refer to Figure 3 Figure 4 and Figure 5

$\mathrm{Int}_{\mathrm{rel}(\mathrm{abs})}$ is directly calculated from absorption data obtained from DFT calculation and $\mathrm{Int}_{\mathrm{rel}(\mathrm{em})}$ is calculated from the emission model. Int $\mathrm{rel}_{(\mathrm{em})}$ shows an average increase of $\sim 35 \%$ from Int ${ }_{\mathrm{rel}(\mathrm{abs})}$.

\footnotetext{
${ }^{a}$ Relative intensity ( Int $_{\mathrm{rel}}$ ) from absorption

${ }^{b}$ Relative intensity $\left(\mathrm{Int}_{\mathrm{rel}}\right)$ from emission model

${ }^{c} \mathrm{C}$-D bond is aromatic in nature

${ }^{d} \mathrm{C}$-D bond is aliphatic in nature
} 
is pure in $\mathrm{D}$ characteristic vibrational modes and may be used to determine the $\mathrm{D} / \mathrm{H}$ ratio. Both the observations made by ISO and AKARI (Peeters et al., 2004; Onaka et al., 2014) estimated a D/H ratio by taking the ratio of band intensities at $\sim 4-5 \mu \mathrm{m}$ to $\sim 3-4 \mu \mathrm{m}$. Peeters et al. (2004) proposed $\mathrm{D} / \mathrm{H}$ ratios of $0.17 \pm 0.03$ in the Orion bar and $0.36 \pm 0.08$ in M17. Onaka et al. (2014) suggested a comparatively low value of $\mathrm{D} / \mathrm{H}(0.03)$ and proposed low deuteration limited to large PAHs. It is implicitly assumed that a molecule can have more than one D (Peeters et al., 2004; Onaka et al., 2014). Thus, emission per $\mathrm{C}-\mathrm{D}$ bond was considered in observations (Peeters et al., 2004; Onaka et al., 2014). This work proposes a $[\mathrm{D} / \mathrm{H}]_{\text {int }}$ that is calculated by taking the ratio of integrated band intensities due to $\mathrm{C}-\mathrm{D}$ stretching to that of $\mathrm{C}-\mathrm{H}$ stretching from the emission model. Deuterated ovalene, deuterated ovalene cation and deuteronated ovalene carry only one $\mathrm{D}$ atom, whereas Dovalene ${ }^{+}$has two $\mathrm{D}$ atoms.

Table 2: Theoretically computed $\mathrm{D} / \mathrm{H}$ ratios in deuterium-containing ovalene variants

\begin{tabular}{|c|c|c|}
\hline PAHs & $\begin{array}{c}\text { no of } \\
\text { D atoms, } n\end{array}$ & {$[\mathrm{D} / \mathrm{H}]_{\mathrm{int}}{ }^{e}$} \\
\hline Deuterated ovalene (aromatic) & 1 & 0.05 \\
\hline Deuterated ovalene isomer 1 (aromatic) & 1 & 0.07 \\
\hline Deuterated ovalene isomer 2 (aromatic) & 1 & 0.05 \\
\hline Deuterated ovalene isomer 3 (aromatic) & 1 & 0.07 \\
\hline Deuterated ovalene (aliphatic) & 1 & 0.06 \\
\hline Deuterated ovalene isomer 1 (aliphatic) & 1 & 0.07 \\
\hline Deuterated ovalene isomer 2 (aliphatic) & 1 & 0.09 \\
\hline Deuterated ovalene isomer 3 (aliphatic) & 1 & 0.1 \\
\hline Deuterated ovalene cation & 1 & 0.11 \\
\hline $\begin{array}{l}\text { Deuterated ovalene cation } \\
\text { isomer } 1\end{array}$ & 1 & 0.13 \\
\hline $\begin{array}{l}\text { Deuterated ovalene cation } \\
\text { isomer } 2\end{array}$ & 1 & 0.13 \\
\hline $\begin{array}{c}\text { Deuterated ovalene cation } \\
\text { isomer } 3 \\
\end{array}$ & 1 & 0.12 \\
\hline Deuteronated ovalene & 1 & 0.04 \\
\hline Deuteronated ovalene isomer 1 & 1 & 0.08 \\
\hline Deuteronated ovalene isomer 2 & 1 & 0.17 \\
\hline Deuteronated ovalene isomer 3 & 1 & 0.12 \\
\hline DovaleneD $^{+}$ & 2 & $0.14(0.07)^{f}$ \\
\hline DovaleneD $^{+}$isomer & 2 & $0.22(0.11) \AA$ \\
\hline
\end{tabular}

$[\mathrm{D} / \mathrm{H}]_{\mathrm{abs}}$ is equal to $[\mathrm{D} / \mathrm{H}]_{\mathrm{int}}$ for all molecules except for Dovalene $\mathrm{D}^{+}$and its isomer as the no of $\mathrm{D}$ atom is one in deuterated ovalene, deuterated ovalene cation and deuteronated ovalene. Dovalene $\mathrm{D}^{+}$and its isomer consist of two $\mathrm{D}$ atoms and thereby give a different $[\mathrm{D} / \mathrm{H}]_{\mathrm{abs}}$ from $[\mathrm{D} / \mathrm{H}]_{\mathrm{int}}$.

\footnotetext{
${ }^{e}[\mathrm{D} / \mathrm{H}]_{\text {int }}=$ intensity of $\mathrm{C}-\mathrm{D}$ stretch/intensity of $\mathrm{C}-\mathrm{H}$ stretch from the emission model

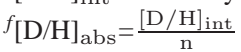


To make a comparative study, a $[\mathrm{D} / \mathrm{H}]_{\text {abs }}$ is computed which is nothing but $[\mathrm{D} / \mathrm{H}]_{\text {int }}$ (intensity of C-D stretch/intensity of C-H stretch) per number of D atoms. Table 2 describes the theoretical $[\mathrm{D} / \mathrm{H}]_{\mathrm{abs}}$ ratios obtained from deuterium-containing ovalene variants. Since intensity is sensitive to the position in which D is substituted and/or added, $[\mathrm{D} / \mathrm{H}]_{\text {abs }}$ shows variation from one isomer to another isomer in all considered PAHs. Such variation is salient for deuteronated ovalene. The calculated $[\mathrm{D} / \mathrm{H}]_{\mathrm{abs}}$ values for deuterated ovalenes are small compared to ISO observation and close to AKARI observation. On the contrary, for deuterated ovalene cations, $[\mathrm{D} / \mathrm{H}]_{\mathrm{abs}}$ values are in close proximity to ISO observations. However, nothing concrete can be deduced by considering a single form of PAH. The observed value of $\mathrm{D} / \mathrm{H}$ that varies from $3 \%$ to 30\% (Peeters et al., 2004; Onaka et al., 2014) indicates a mixture of deuterated PAHs, if present in the ISM. In our recent study (Buragohain et al., 2015), a $[\mathrm{D} / \mathrm{H}]_{\mathrm{sc}}$ ratio has been derived for a set of different molecules which is comparable to observation made by $I S O$ and $A K A R I$. The $[\mathrm{D} / \mathrm{H}]_{\mathrm{sc}}$ ratio is simply $[\mathrm{D} / \mathrm{H}]_{\mathrm{int}} /[\mathrm{D} / \mathrm{H}]_{\mathrm{num}} 8$. In our present work, we have made similar calculations for ionized forms of deuterated ovalene as ionization of molecules is likely to occur in the ISM. This has been compared with our previous results (Buragohain et al., 2015). Table 3 lists the $[\mathrm{D} / \mathrm{H}]_{\mathrm{sc}}$ ratios from our previous as well as present results. The molecules are chosen in terms of increasing size. If the observed $\mathrm{D} / \mathrm{H}$ ratio is lower than the calculated $[\mathrm{D} / \mathrm{H}]_{\mathrm{sc}}$ ratio, it suggests a mixture of pure, deuterated, deuteronated and/or other substituted PAH molecules.

D/H ratios provided by Peeters et al. (2004) and Onaka et al. (2014) may be used to estimate the size of the deuterium-containing PAH variants in the ISM by comparing with the theoretically obtained $\mathrm{D} / \mathrm{H}$ ratio. Our results from previous work

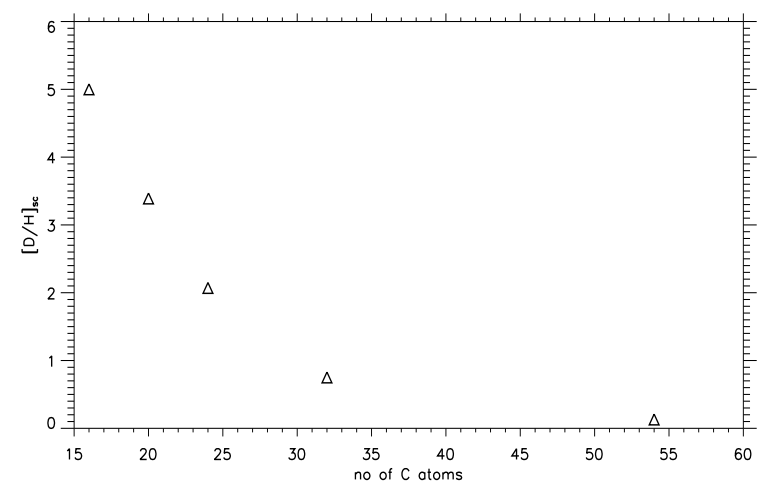

Figure 7: $[\mathrm{D} / \mathrm{H}]_{\mathrm{sc}}$ ratio with increasing size, no of $\mathrm{C}$ atoms is directly proportional to size of PAH molecule

Buragohain et al., 2015) and the present report suggest a $[\mathrm{D} / \mathrm{H}]_{\mathrm{sc}}$ ratio (Table 3 ) that is large compared to the Peeters et al. (2004) and Onaka et al. (2014) observations except for deuteronated ovalene and deuteronated circumcoronene. The three isomers of

${ }^{8}[\mathrm{D} / \mathrm{H}]_{\mathrm{num}}=\frac{\text { no of } \mathrm{D} \text { atoms }}{\text { no of } \mathrm{H} \text { atoms }}$ 
Table 3: $[\mathrm{D} / \mathrm{H}]_{\mathrm{sc}}$ ratios calculated for $\mathrm{DPAH}^{+}$

\begin{tabular}{|c|c|}
\hline $\mathrm{DPAH}^{+}$ & {$[\mathrm{D} / \mathrm{H}]_{\mathrm{sc}} g$} \\
\hline Deuteronated pyrene $^{h}$ & 5.00 \\
\hline Deuteronated perylene $h$ & 3.39 \\
\hline Deuteronated coronene & 2.71 \\
\hline DcorD $^{+} h$ & 1.43 \\
\hline Deuterated ovalene cation ${ }^{i}$ & 1.38 \\
\hline Deuterated ovalene cation isomer 1$]^{i}$ & 1.63 \\
\hline Deuterated ovalene cation isomer $2^{i]}$ & 1.63 \\
\hline Deuterated ovalene cation isomer 3 & 1.50 \\
\hline Deuteronated ovalene & 0.57 \\
\hline Deuteronated ovalene isomer $1_{[}^{[]}$ & 1.14 \\
\hline Deuteronated ovalene isomer $2 \frac{i}{\underline{i}}$ & 2.43 \\
\hline Deuteronated ovalene isomer $3 i$ & 1.71 \\
\hline DovaleneD $^{+}$ & 0.93 \\
\hline DovaleneD $^{+}$isomer & 1.47 \\
\hline Deuteronated circumcoronene & 0.13 \\
\hline $\begin{array}{l}{ }^{g}[\mathrm{D} / \mathrm{H}]_{\mathrm{Sc}}=\frac{[\mathrm{D} / \mathrm{H}]_{\mathrm{int}}}{[\mathrm{D} / \mathrm{H}]_{\text {n+1m }}} \\
h \sqrt{\text { Buragohain et al. }}, \mid 2015) \\
{ }^{i} \text { present work }\end{array}$ & \\
\hline
\end{tabular}

deuteronated ovalene show a larger value of $[\mathrm{D} / \mathrm{H}]_{\mathrm{sc}}$. With increasing size, the $[\mathrm{D} / \mathrm{H}]_{\mathrm{sc}}$ ratio tends to decrease (Figure 7). For a particular molecule, addition of more than one deuterium may or may not lead to an increase in the $[\mathrm{D} / \mathrm{H}]_{\mathrm{sc}}$ ratio. $[\mathrm{D} / \mathrm{H}]_{\mathrm{sc}}$ ratios for deuteronated ovalene and deuteronated circumcoronene are in close proximity to the $\mathrm{D} / \mathrm{H}$ ratio observed by Peeters et al. (2004) and hence may be considered as feasible carriers for bands at $4-5 \mu \mathrm{m}$. $[\mathrm{D} / \mathrm{H}]_{\mathrm{sc}}$ ratios suggested by our work do not match with $A K A R I$ observation. It is suggested that PAH molecules close to 100 carbon atoms may match the observed $\mathrm{D} / \mathrm{H}$ ratio by $A K A R I$.

Doney et al. (2016) observed H II regions in the Milky Way in near infrared in order to estimate the amount of deuterium in PAHs. They did not detect emission from deuterated PAHs towards all the sources and concluded that the deuteration of PAHs is not common. Doney et al. (2016) calculated emission spectrum for molecule with aliphatic group attached to the PAH structure and calculated a D/H ratio in the range of $0.01-0.06$ by taking the intensity ratio of 3.3 and $4.75 \mu \mathrm{m}$ band. Our approach is different from Doney et al. (2016) and the $[\mathrm{D} / \mathrm{H}]_{\text {int }}$ ratio is calculated by taking the ratio of integrated band intensities of both aromatic and aliphatic $\mathrm{C}-\mathrm{D}$ stretching to integrated band intensities of both aromatic and aliphatic $\mathrm{C}-\mathrm{H}$ stretching for our sample molecules. The calculated $[\mathrm{D} / \mathrm{H}]_{\text {int }}$ in our work for solo deuteration is in the range of 0.04-0.17. The molecules with an aliphatic side group however are feasible only in benign environments and may be destroyed in a harsh interstellar environment such as fully evolved planetary nebulae or H II regions (Bernstein et al., 1996). 


\section{Conclusion}

Deuterium-containing PAH variants have been studied theoretically in relation to mid-infrared emission bands. This report suggests PAH molecules with deuterium content as potential candidate carriers for some of the observed UIR features in the ISM on basis of the band positions. PAHs with a $\mathrm{D}$ or $\mathrm{D}^{+}$give features in the $4-5 \mu \mathrm{m}$ region which arises purely due to the stretching of the $\mathrm{C}-\mathrm{D}$ bond and hence may be considered responsible for observed bands at $4.4 \mu \mathrm{m}$ and $4.65 \mu \mathrm{m}$. To gain further support, the $[\mathrm{D} / \mathrm{H}]_{\mathrm{sc}}$ ratio for ovalene with $\mathrm{D}$ is estimated. On comparing this ratio from the present and previous reports with observations, it is realized that deuteronated ovalene and deuteronated circumcoronene agree with the observations of Peeters et al. (2004). $A K A R I$ observations propose comparatively large PAHs (no. of $\mathrm{C}$ atoms $\sim 100$ ) with low deuterium content. PAHs with a suitable $[\mathrm{D} / \mathrm{H}]_{\mathrm{sc}}$ may be arranged accordingly for much more expensive laboratory experiments which are of utmost importance for assignment of carriers. The study of deuterium-containing PAHs is essential in order to measure $\mathrm{D} / \mathrm{H}$ that will give insight into the history of star formation. This study can further be progressed to estimate $\mathrm{HD} / \mathrm{H}_{2}$ ratio in interstellar gas. For reliable analysis, more experimental and observational evidence of interstellar deuterium is needed.

\section{Acknowledgements}

We thank the anonymous referee for their critical comments that have helped in improving the manuscript. MB is a junior research fellow in a SERB - DST FAST TRACK project. AP acknowledges financial support from SERB DST FAST TRACK grant (SERB/F/5143/2013-2014) and AP, TO and IS acknowledge support from the DST - JSPS grant (DST/INT/JSPS/P-189/2014). AP thanks the Inter-University Centre for Astronomy and Astrophysics, Pune for associateship. PJS thanks the Leverhulme Trust for award of a Research Fellowship and Leiden Observatory for hospitality that allowed completion of this work.

\section{REFERENCES}

\section{References}

Abergel, A., Bernard, J. P., Boulanger, F., Cesarsky, D., Falgarone, E., Jones, A., Miville-Deschenes, M.-A., Perault, M., Puget, J.-L., Huldtgren, M., Kaas, A. A., Nordh, L., Olofsson, G., André, P., Bontemps, S., Casali, M. M., Cesarsky, C. J., Copet, M. E., Davies, J., Montmerle, T., Persi, P., Sibille, F., 2002. Evolution of very small particles in the southern part of Orion B observed by ISOCAM. A\&A389, 239-251.

Acke, B., van den Ancker, M. E., 2004. ISO spectroscopy of disks around Herbig Ae/Be stars. A\&A426, 151-170.

Allamandola, L. J., Hudgins, D. M., Sandford, S. A., 1999. Modeling the Unidentified Infrared Emission with Combinations of Polycyclic Aromatic Hydrocarbons. ApJ511, L115-L119. 
Allamandola, L. J., Sandford, S. A., Wopenka, B., 1987. Interstellar polycyclic aromatic hydrocarbons and carbon in interplanetary dust particles and meteorites. Science $237,56-59$.

Allamandola, L. J., Tielens, A. G. G. M., Barker, J. R., 1985. Polycyclic aromatic hydrocarbons and the unidentified infrared emission bands - Auto exhaust along the Milky Way. ApJ290, L25-L28.

Allamandola, L. J., Tielens, A. G. G. M., Barker, J. R., 1989. Interstellar polycyclic aromatic hydrocarbons - The infrared emission bands, the excitation/emission mechanism, and the astrophysical implications. ApJS71, 733-775.

Alvaro Galué, H., Pirali, O., Oomens, J., 2010. Gas-phase infrared spectra of cationized nitrogen-substituted polycyclic aromatic hydrocarbons. A\&A517, A15.

Bakes, E. L. O., Tielens, A. G. G. M., 1994. The photoelectric heating mechanism for very small graphitic grains and polycyclic aromatic hydrocarbons. ApJ427, 822838.

Bauschlicher, C. W., Langhoff, S. R., 1997. The calculation of accurate harmonic frequencies of large molecules: the polycyclic aromatic hydrocarbons, a case study. Spectrochimica Acta Part A: Molecular Spectroscopy 53, 1225-1240.

Bauschlicher, C. W., Langhoff, S. R., Sandford, S. A., Hudgins, D. M., 1997. Infrared Spectra of Perdeuterated Naphthalene, Phenanthrene, Chrysene, and Pyrene. Journal of Physical Chemistry A 101, 2414-2422.

Bauschlicher, Jr., C. W., Boersma, C., Ricca, A., Mattioda, A. L., Cami, J., Peeters, E., Sánchez de Armas, F., Puerta Saborido, G., Hudgins, D. M., Allamandola, L. J., 2010. The NASA Ames Polycyclic Aromatic Hydrocarbon Infrared Spectroscopic Database: The Computed Spectra. ApJS189, 341-351.

Berné, O., Montillaud, J., Joblin, C., 2015. Top-down formation of fullerenes in the interstellar medium. A\&A577, A133.

Bernstein, M. P., Sandford, S. A., Allamandola, L. J., 1996. Hydrogenated Polycyclic Aromatic Hydrocarbons and the 2940 and 2850 Wavenumber (3.40 and 3.51 micron) Infrared Emission Features. ApJ472, L127.

Buragohain, M., Pathak, A., Sarre, P., Onaka, T., Sakon, I., 2015. Theoretical study of deuteronated PAHs as carriers for IR emission features in the ISM. MNRAS454, 193-204.

Campbell, E. K., Holz, M., Gerlich, D., Maier, J. P., 2015. Laboratory confirmation of $\mathrm{C}_{60}{ }^{+}$as the carrier of two diffuse interstellar bands. Nature 523, 322-323.

Candian, A., Sarre, P. J., Tielens, A. G. G. M., 2014. Polycyclic Aromatic Hydrocarbons with Armchair Edges and the $12.7 \mu \mathrm{m}$ Band. ApJ791, L10. 
Cook, D. J., Saykally, R. J., 1998. Simulated Infrared Emission Spectra of Highly Excited Polyatomic Molecules: A Detailed Model of the PAH-UIR Hypothesis. ApJ493, 793-802.

Cox, N. L. J., Cordiner, M. A., Cami, J., Foing, B. H., Sarre, P. J., Kaper, L., Ehrenfreund, P., 2006. The Large Magellanic Cloud: diffuse interstellar bands, atomic lines and the local environmental conditions. A\&A447, 991-1009.

Crawford, M. K., Tielens, A. G. G. M., Allamandola, L. J., 1985. Ionized polycyclic aromatic hydrocarbons and the diffuse interstellar bands. ApJ293, L45-L48.

DeFrees, D. J., Miller, M. D., Talbi, D., Pauzat, F., Ellinger, Y., 1993. Theoretical infrared spectra of some model polycyclic aromatic hydrocarbons - Effect of ionization. ApJ408, 530-538.

Doney, K. D., Candian, A., Mori, T., Onaka, T., Tielens, A. G. G. M., 2016. Deuterated polycyclic aromatic hydrocarbons: Revisited. A\&A586, A65.

Draine, B. T., 2006. Can Dust Explain Variations in the D/H Ratio? In: Sonneborn, G., Moos, H. W., Andersson, B.-G. (Eds.), Astrophysics in the Far Ultraviolet: Five Years of Discovery with FUSE. Vol. 348 of Astronomical Society of the Pacific Conference Series. p. 58.

Duley, W. W., Williams, D. A., 1981. The infrared spectrum of interstellar dust - Surface functional groups on carbon. MNRAS196, 269-274.

Ehrenfreund, P., Foing, B., 2015. Astrochemistry: Fullerene solves an interstellar puzzle. Nature 523 (7560), 296-297.

Gillett, F. C., Forrest, W. J., Merrill, K. M., 1973.8 - 13-micron spectra of NGC 7027, $\mathrm{BD}+30$ 3639, and NGC 6572. ApJ183, 87-93.

Hony, S., Van Kerckhoven, C., Peeters, E., Tielens, A. G. G. M., Hudgins, D. M., Allamandola, L. J., 2001. The CH out-of-plane bending modes of PAH molecules in astrophysical environments. A\&A370, 1030-1043.

Hudgins, D. M., Bauschlicher, Jr., C. W., Allamandola, L. J., 2001. Closed-shell polycyclic aromatic hydrocarbon cations: a new category of interstellar polycyclic aromatic hydrocarbons. Spectrochimica Acta 57, 907-930.

Hudgins, D. M., Bauschlicher, Jr., C. W., Sandford, S. A., 2004. The Impact of Deuteration on the Infrared Spectra of Interstellar Polycyclic Aromatic Hydrocarbons. ApJ614, 770-780.

Hudgins, D. M., Sandford, S. A., 1998a. Infrared spectroscopy of matrix isolated polycyclic aromatic hydrocarbons. 1. pahs containing two to four rings. The Journal of Physical Chemistry A 102 (2), 329-343.

Hudgins, D. M., Sandford, S. A., 1998b. Infrared spectroscopy of matrix isolated polycyclic aromatic hydrocarbons. 2. pahs containing five or more rings. The Journal of Physical Chemistry A 102 (2), 344-352. 
Jenkins, E. B., Tripp, T. M., Woźniak, P. R., Sofia, U. J., Sonneborn, G., 1999. Spatial Variability in the Ratio of Interstellar Atomic Deuterium to Hydrogen. I. Observations toward $\delta$ Orionis by the Interstellar Medium Absorption Profile Spectrograph. ApJ520, 182-195.

Klærke, B., Toker, Y., Rahbek, D. B., Hornekær, L., Andersen, L. H., 2013. Formation and stability of hydrogenated PAHs in the gas phase. A\&A549, A84.

Langhoff, S. R., 1996. Theoretical infrared spectra for polycyclic aromatic hydrocarbon neutrals, cations, and anions. The Journal of Physical Chemistry 100 (8), 28192841.

Langhoff, S. R., Bauschlicher, C. W., Hudgins, D. M., Sandford, S. A., Allamandola, L. J., 1998. Infrared spectra of substituted polycyclic aromatic hydrocarbons. The Journal of Physical Chemistry A 102 (9), 1632-1646.

Léger, A., d'Hendecourt, L., 1985. Are polycyclic aromatic hydrocarbons the carriers of the diffuse interstellar bands in the visible? A\&A146, 81-85.

Léger, A., Puget, J. L., 1984. Identification of the 'unidentified' IR emission features of interstellar dust? A\&A137, L5-L8.

Lepp, S., Dalgarno, A., 1988. Polycyclic aromatic hydrocarbons in interstellar chemistry. ApJ324, 553-556.

Linsky, J. L., Draine, B. T., Moos, H. W., Jenkins, E. B., Wood, B. E., Oliveira, C., Blair, W. P., Friedman, S. D., Gry, C., Knauth, D., Kruk, J. W., Lacour, S., Lehner, N., Redfield, S., Shull, J. M., Sonneborn, G., Williger, G. M., 2006. What Is the Total Deuterium Abundance in the Local Galactic Disk? ApJ647, 1106-1124.

Malloci, G., Joblin, C., Mulas, G., 2007. Theoretical evaluation of PAH dication properties. A\&A462, 627-635.

Malloci, G., Mulas, G., Cecchi-Pestellini, C., Joblin, C., 2008. Dehydrogenated polycyclic aromatic hydrocarbons and UV bump. A\&A489, 1183-1187.

Mattila, K., Lemke, D., Haikala, L. K., Laureijs, R. J., Léger, A., Lehtinen, K., Leinert, C., Mezger, P. G., 1996. Spectrophotometry of UIR bands in the diffuse emission of the galactic disk. A\&A315, L353-L356.

Mattioda, A. L., Hudgins, D. M., Bauschlicher, C. W., Allamandola, L. J., 2005. Infrared spectroscopy of matrix-isolated polycyclic aromatic compounds and their ions. 7. Phenazine, a dual substituted polycyclic aromatic nitrogen heterocycle. Advances in Space Research 36, 156-165.

Moos, H. W., Sembach, K. R., Vidal-Madjar, A., York, D. G., Friedman, S. D., Hébrard, G., Kruk, J. W., Lehner, N., Lemoine, M., Sonneborn, G., Wood, B. E., Ake, T. B., André, M., Blair, W. P., Chayer, P., Gry, C., Dupree, A. K., Ferlet, R., Feldman, P. D., Green, J. C., Howk, J. C., Hutchings, J. B., Jenkins, E. B., Linsky, J. L., Murphy, E. M., Oegerle, W. R., Oliveira, C., Roth, K., Sahnow, D. J., 
Savage, B. D., Shull, J. M., Tripp, T. M., Weiler, E. J., Welsh, B. Y., Wilkinson, E., Woodgate, B. E., 2002. Abundances of Deuterium, Nitrogen, and Oxygen in the Local Interstellar Medium: Overview of First Results from the FUSE Mission. ApJS140, 3-17.

Mulas, G., Malloci, G., Benvenuti, P., 2003. Testing the "strong" PAHs hypothesis. II. A quantitative link between DIBs and far-IR emission features. A\&A410, 639-648.

Onaka, T., Mori, T. I., Sakon, I., Ohsawa, R., Kaneda, H., Okada, Y., Tanaka, M., 2014. Search for the Infrared Emission Features from Deuterated Interstellar Polycyclic Aromatic Hydrocarbons. ApJ780, 114.

Onaka, T., Yamamura, I., Tanabe, T., Roellig, T. L., Yuen, L., 1996. Detection of the Mid-Infrared Unidentified Bands in the Diffuse Galactic Emission by IRTS. PASJ48, L59-L63.

Oomens, J., Tielens, A. G. G. M., Sartakov, B. G., von Helden, G., Meijer, G., 2003. Laboratory Infrared Spectroscopy of Cationic Polycyclic Aromatic Hydrocarbon Molecules. ApJ591, 968-985.

Pathak, A., Rastogi, S., 2005. Computational study of neutral and cationic catacondensed polycyclic aromatic hydrocarbons. Chemical Physics 313, 133-150.

Pathak, A., Rastogi, S., 2006. Computational study of neutral and cationic pericondensed polycyclic aromatic hydrocarbons. Chemical Physics 326, 315-328.

Pathak, A., Rastogi, S., 2007. Theoretical infrared spectra of large polycyclic aromatic hydrocarbons. Spectrochimica Acta Part A: Molecular Spectroscopy 67, 898-909.

Pathak, A., Rastogi, S., 2008. Modeling the interstellar aromatic infrared bands with co-added spectra of PAHs. A\&A485, 735-742.

Pathak, A., Sarre, P. J., 2008. Protonated PAHs as carriers of diffuse interstellar bands. MNRAS391, L10-L14.

Pauzat, F., Lattelais, M., Ellinger, Y., Minot, C., 2011. The interstellar carbonaceous aromatic matter as a trap for molecular hydrogen. MNRAS412, 2729-2734.

Pech, C., Joblin, C., Boissel, P., 2002. The profiles of the aromatic infrared bands explained with molecular carriers. A\&A388, 639-651.

Peeters, E., Allamandola, L. J., Bauschlicher, Jr., C. W., Hudgins, D. M., Sandford, S. A., Tielens, A. G. G. M., 2004. Deuterated Interstellar Polycyclic Aromatic Hydrocarbons. ApJ604, 252-257.

Peeters, E., Hony, S., Van Kerckhoven, C., Tielens, A. G. G. M., Allamandola, L. J., Hudgins, D. M., Bauschlicher, C. W., 2002. The rich 6 to $9 \mathrm{vec}$ mu m spectrum of interstellar PAHs. A\&A390, 1089-1113.

Roser, J. E., Ricca, A., Allamandola, L. J., 2014. Anthracene Clusters and the Interstellar Infrared Emission Features. ApJ783, 97. 
Sakon, I., Onaka, T., Ishihara, D., Ootsubo, T., Yamamura, I., Tanabé, T., Roellig, T. L., 2004. The Unidentified Infrared Bands in the Diffuse Interstellar Medium across the Galaxy Based on the Infrared Telescope in Space Mid-Infrared Spectrometer Observation. ApJ609, 203-219.

Salama, F., Bakes, E. L. O., Allamandola, L. J., Tielens, A. G. G. M., 1996. Assessment of the Polycyclic Aromatic Hydrocarbon-Diffuse Interstellar Band Proposal. ApJ458, 621.

Salama, F., Galazutdinov, G. A., Krełowski, J., Biennier, L., Beletsky, Y., Song, I.O., 2011. Polycyclic Aromatic Hydrocarbons and the Diffuse Interstellar Bands: A Survey. ApJ728, 154.

Sandford, S. A., Bernstein, M. P., Allamandola, L. J., Gillette, J. S., Zare, R. N., 2000. Deuterium Enrichment of Polycyclic Aromatic Hydrocarbons by Photochemically Induced Exchange with Deuterium-rich Cosmic Ices. ApJ538, 691-697.

Sellgren, K., 1984. The near-infrared continuum emission of visual reflection nebulae. ApJ277, 623-633.

Shao, Y., et al., 2015. Advances in molecular quantum chemistry contained in the qchem 4 program package. Mol. Phys. 113, 184-215.

Simon, A., Rapacioli, M., Lanza, M., Joalland, B., Spiegelman, F., 2011. Molecular dynamics simulations on $[\mathrm{FePAH}]+\pi$-complexes of astrophysical interest: anharmonic infrared spectroscopy. Physical Chemistry Chemical Physics (Incorporating Faraday Transactions) 13, 3359 .

Sonneborn, G., Tripp, T. M., Ferlet, R., Jenkins, E. B., Sofia, U. J., Vidal-Madjar, A., Woźniak, P. R., 2000. Spatial Variability in the Ratio of Interstellar Atomic Deuterium to Hydrogen. II. Observations toward $\gamma^{2}$ Velorum and $\zeta$ Puppis by the Interstellar Medium Absorption Profile Spectrograph. ApJ545, 277-289.

Steigman, G., 2003. On the Variation of Deuterium and Oxygen Abundances in the Local Interstellar Medium. ApJ586, 1120-1126.

Szczepanski, J., Ekern, S., Chapo, C., Vala, M., 1996. Infrared spectroscopy of matrixisolated carbon clusters, with emphasis on $\mathrm{C}_{8}$ and $\mathrm{C}_{9}$. Chemical Physics 211, 359366.

Tielens, A. G. G. M., 1983. Surface chemistry of deuterated molecules. A\&A119, 177184.

Tielens, A. G. G. M., 1992. The D/h Ratio in Molecular Clouds(rp). In: Singh, P. D. (Ed.), Astrochemistry of Cosmic Phenomena. Vol. 150 of IAU Symposium. p. 91.

Tielens, A. G. G. M., 1997. Deuterium and interstellar chemical processes. In: Bernatowicz, T. J., Zinner, E. (Eds.), American Institute of Physics Conference Series. Vol. 402 of American Institute of Physics Conference Series. pp. 523-544. 
Tielens, A. G. G. M., 2008. Interstellar Polycyclic Aromatic Hydrocarbon Molecules. ARA\&A46, 289-337.

Verstraete, L., Léger, A., d'Hendecourt, L., Defourneau, D., Dutuit, O., 1990. Ionization cross-section measurements for two PAH molecules - Implications for the heating of diffuse interstellar gas. A\&A237, 436-444.

Verstraete, L., Pech, C., Moutou, C., Sellgren, K., Wright, C. M., Giard, M., Léger, A., Timmermann, R., Drapatz, S., 2001. The Aromatic Infrared Bands as seen by ISO-SWS: Probing the PAH model. A\&A372, 981-997.

Verstraete, L., Puget, J. L., Falgarone, E., Drapatz, S., Wright, C. M., Timmermann, R., 1996. SWS spectroscopy of small grain features across the M17-Southwest photodissociation front. A\&A315, L337-L340.

Wood, B. E., Linsky, J. L., Hébrard, G., Williger, G. M., Moos, H. W., Blair, W. P., 2004. Two New Low Galactic D/H Measurements from the Far Ultraviolet Spectroscopic Explorer. ApJ609, 838-853. 